\title{
Réplique de Messieurs Yvan Lamonde et Daniel Leblanc au compte rendu de Joanne Burgess sur La culture ouvrière à Montréal (1880-1920) : bilan historiographique (RHAF, 37, 1 (juin 1983) : 103-104).
}

Yvan Lamonde et Daniel Leblanc

Volume 37, numéro 3, décembre 1983

URI : https://id.erudit.org/iderudit/304194ar

DOI : https://doi.org/10.7202/304194ar

Aller au sommaire du numéro

Éditeur(s)

Institut d'histoire de l'Amérique française

ISSN

0035-2357 (imprimé)

1492-1383 (numérique)

Découvrir la revue

Citer ce document

Lamonde, Y. \& Leblanc, D. (1983). Réplique de Messieurs Yvan Lamonde et Daniel Leblanc au compte rendu de Joanne Burgess sur La culture ouvrière à Montréal (1880-1920) : bilan historiographique (RHAF, 37, 1 (juin 1983) :

103-104). Revue d'histoire de l'Amérique française, 37(3), 472-473.

https://doi.org/10.7202/304194ar d'utilisation que vous pouvez consulter en ligne. 
Réplique de Messieurs Yvan Lamonde et Daniel Leblanc au compte rendu de Joanne Burgess sur La culture ouvrière à Montréal (1880-1920): bilan historiographique (RHAF, 37,1 (juin 1983): 103-104).

Le compte rendu de notre ouvrage sur La culture ouvrière à Montréal (1880-1920). Bilan historiographique par Joanne Burgess dans la RHAF (37, 1 , juin 1983, pp. 103-104) appelle des commentaires et une remise en perspectives.

On semble avoir oublié qu'il s'agit «d'un bilan des connaissances acquises» (p. 14) et non des connaissances souhaitées, qu'il s'agit d'une mise en place des composantes (p. 152) jusqu'ici laissées éparses et non de la fixation d'un cadre théorique.

J. Burgess s'est méprise sur le sens de notre parcours de l'historiographie internationale sur la culture ouvrière; celui-ci ne devait pas servir à fixer un cadre théorique mais bien plutôt à «enrichir» (p. 14) la présentation d'une problématique, la mise en place d'aspects de la culture ouvrière montréalaise jusque-là complètement fragmentée. J. Burgess ne s'arrête précisément pas à ce qui a fait l'objet premier de cet ouvrage, le rassemblement et l'ordonnance des connaissances sur la culture ouvrière à Montréal. 
L'auteur aurait dû aussi saisir que notre approche, sans tenir un discours interminable, questionnait précisément un certain courant d'analyse de la culture populaire rapidement définie et souvent identifiée à la culture de masse et que cette approche tentait justement de restituer un sens véritable à cette culture en l'associant à la culture ouvrière. Quelle lecture J. Burgess a-t-elle donc faite de notre «question de départ» (p. 14) et de nos conclusions (p. 152)? Pourquoi n'a-t-elle pas vu que notre questionnement impliquait une familiarité et une intégration originale de l'historiographie en histoire de la culture savante, populaire, urbaine et ouvrière qui permettaient précisément une problématique inédite abondamment soulignée en introduction et en conclusion?

Si nous n'avions pas été sensibles aux relations entre classes et culture, comme le prétend J. Burgess, aurions-nous fait ce livre, aurions-nous consacré un chapitre aux «Perceptions de classes», aurions-nous souligné, par exemple, l'attitude de la bourgeoisie face à l'instruction primaire (p. 84)? Quant à notre présentation de la culture des autres classes, ce ne pouvait être l'objet de ce bouquin - (un à la fois!) et doit-on le répéter, cette présentation reflète adéquatement l'état de nos connaissances actuelles et non de celles à être publiées dans un an ou deux.

La culture ouvrière que nous décrivons n'est ni «achevée», ni «homogène», ni «finie»; une attention aux nuances aurait fait noter à l'auteur que nous parlons de culture artisanale et de culture ouvrière «industrielle» (p. 149), que nous «souhaitons» des recherches - à venir! - sur les «survivances» dans la culture ouvrière, sur «les continuités et les discontinuités» (p. 151); une attention au texte et aux nuances lui aurait évité de sauter à pieds joints sur des mots («se fondre», p. 91) et lui aurait fait retenir que nous parlons de «mutations», de déculturation «progressive, totale ou partielle» (p. 149). Estce là une culture achevée, homogène, finie?

Du même souffle, J. Burgess déplore notre manque de sensibilité à la notion - certes controversée - de contrôle social et ... «l'évocation répétée» (sic!) des mécanismes de contrôle social; elle poursuit en qualifiant notre analyse de ces mécanismes de contrôle social de «projets machiavéliques de la bourgeoisie». Des références, s.v.p.! Car ce ne sont certainement pas les propos que nous tenons (par exemple, p. 151) qui justifient un tel commentaire.

J. Burgess nous fait faire des généralisations que nous ne faisons pas et s'étonne que «les effets des appartenances ethniques et nationales s'estompent». Lorsque nous écrivons, à propos du logement (p. 69) qu' «habiter SteMarie ou habiter Ste-Anne», la comparaison est ici ponctuelle, renvoie à un même partage social et n'annule pas, ici ou ailleurs, les signes de l'appartenance ethnique. Même si nous y fûmes attentifs à propos des quartiers, des familles (p. 75), de l'instruction (p. 83) ou des bibliothèques (pp. 86-87) par exemple. Ces différences ethniques tout comme d'autres dimensions de cette culture n'ont certes pas fait l'objet d'analyses minimalement éclairantes et définitives et nous «souhaitons» que les travaux à venir de l'auteur et de d'autres les révèlent et les qualifient. 